\title{
Supporting Information Post plasma catalysis for the removal of acetaldehyde using Mn-Co/HZSM-5 catalysts
}

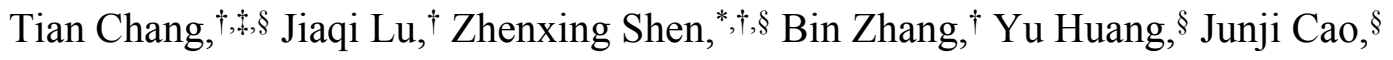

Hongxia Liu, ${ }^{\dagger}$ Savita K.P. Veerapandian, ${ }^{\star}$ Nathalie De Geyter, $₫$ Rino Morent

†Department of Environmental Sciences and Engineering, Xi'an Jiaotong University, Xi'an 710049, China

Research Unit Plasma Technology, Department of Applied Physics, Faculty of Engineering and Architecture, Ghent University, Sint-Pietersnieuwstraat 41-B4, 9000 Ghent, Belgium

$\S$ Key Lab of Aerosol Chemistry \& Physics, SKLLQG, Institute of Earth Environment, Chinese Academy of Sciences, Xi'an 710049, China

*Author to whom correspondence should be addressed. E-mail: zxshen@mail.xjtu.edu.cn (Zhenxing Shen). 

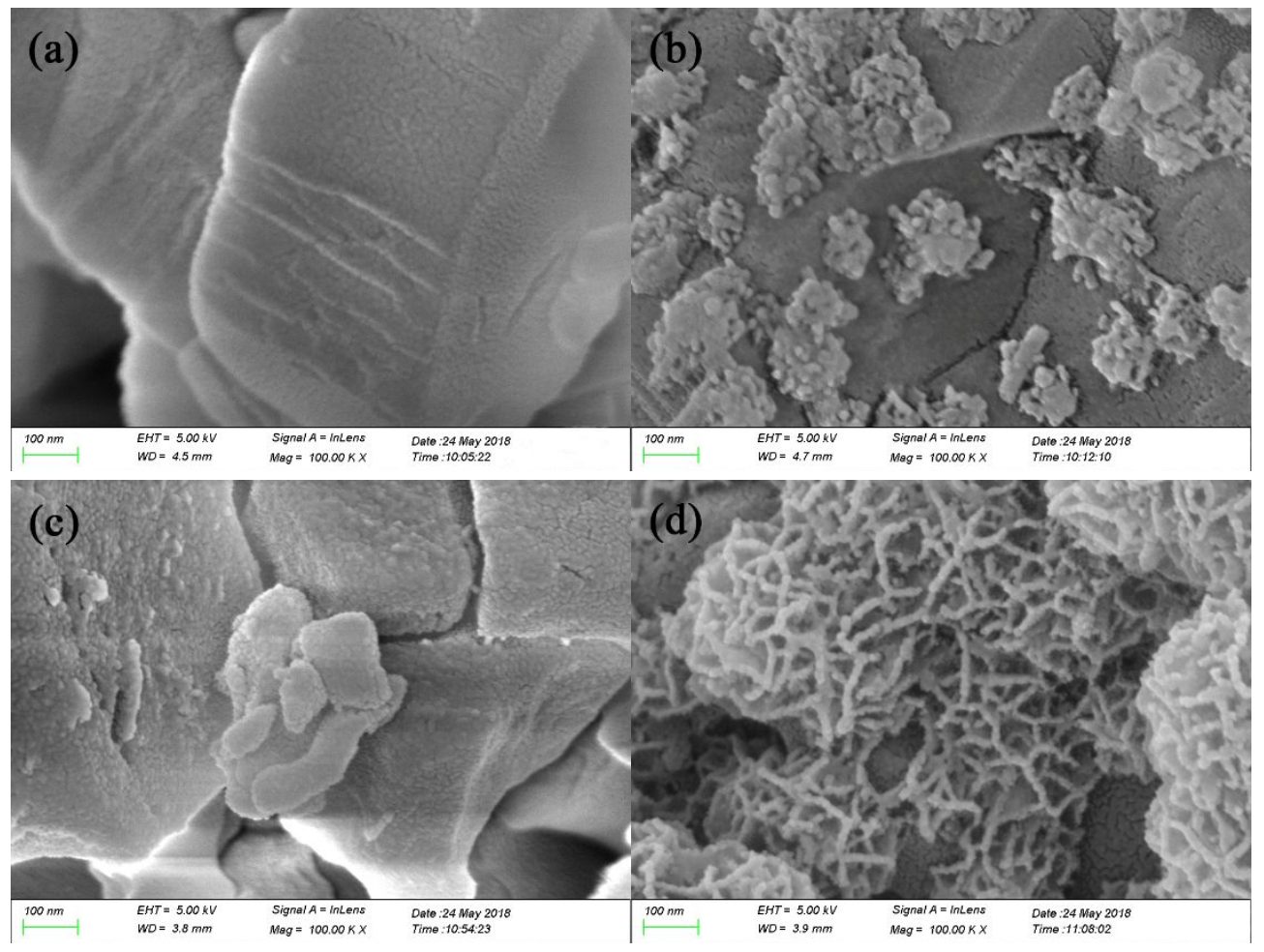

Figure S1. SEM images of (a) HZSM-5, (b) Mn/HZ-5, (c) Co/HZ-5 and (d) MnCo/HZ-5

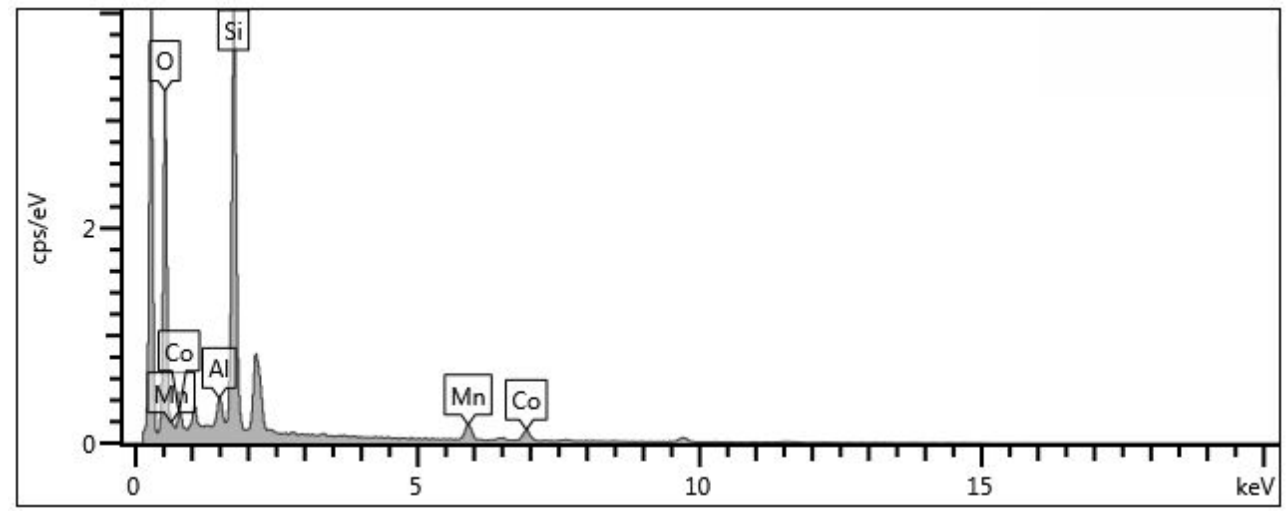




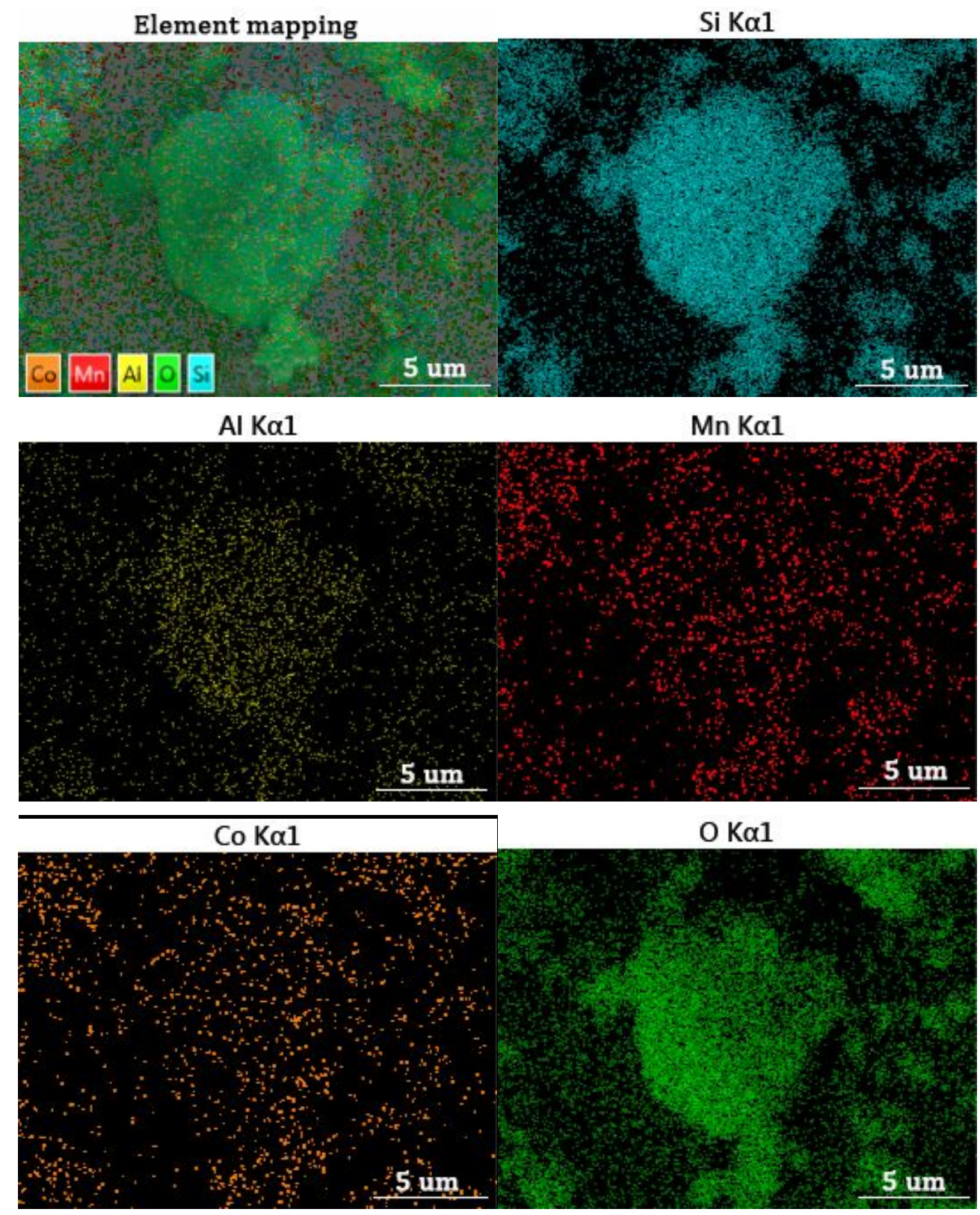

Figure S2. EDX mapping of MnCo/HZ-5 catalyst 


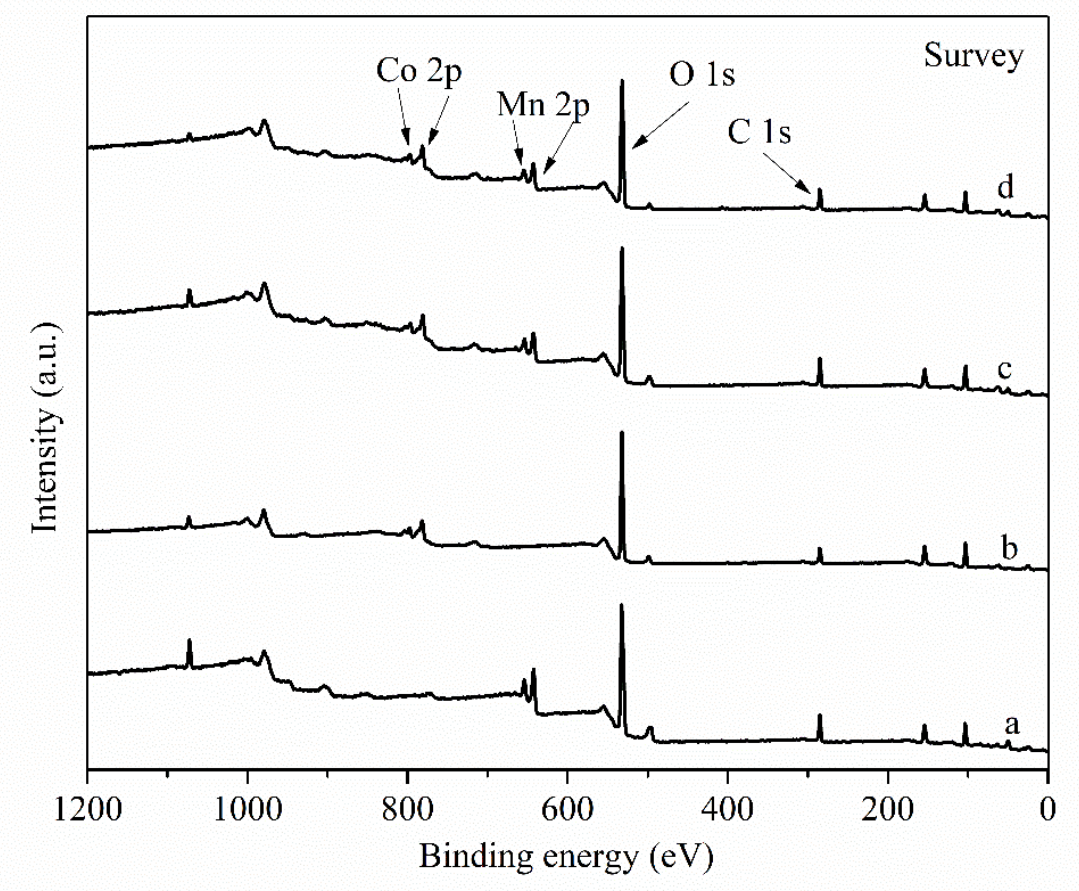

Figure S3. XPS survey spectra of (a) Mn/HZ-5 (fresh), (b) Co/HZ-5 (fresh), (c) MnCo/HZ-5 (fresh) and (d) MnCo/HZ-5 (used) 